\title{
LA NORMA COMO HERRAMIENTA PARA LA REFLEXIÓN GRAMATICAL
}

LEONARDO GÓMEZ TORREGO

CSIC

Cuando uno se plantea cuestiones normativas sobre la (in)corrección de una pronunciación, de un acento, de una forma gramatical escrita en una, dos o más palabras, de un régimen sintáctico, de la adecuación de un género gramatical, de una concordancia o discordancia, de combinaciones sintácticas concretas, etc., surge siempre la curiosidad científica del porqué de la (in)corrección. Ello obliga necesariamente a hurgar en la configuración del sistema linguístico y en las reglas que lo rigen, así como, en muchos casos, en sus vaivenes históricos. Y he de decir que no siempre es fácil explicar por qué un fenómeno se considera incorrecto en un estado de lengua concreto. La prueba de que esto es así es que las normas de (in)corrección académicas cambian con frecuencia y cada vez con mayor rapidez. Por otra parte, el plantearse cuestiones normativas nos hace pensar en la fragilidad e inconsistencia de muchas de las normas $y$, posiblemente, en el desconocimiento de algunos comportamientos del sistema. $\mathrm{Si}$ a todo esto se añade que, para ciertas cuestiones dudosas, los normativistas no tienen una clara respuesta, estaremos en condiciones de reconocer que los planteamientos normativos son un buen acicate para la reflexión gramatical, y que algunas respuestas a las dudas surgen tras un minucioso y ponderado análisis del funcionamiento interno del sistema linguístico o de sus condiciones externas.

A una de las conclusiones a que nos lleva el planteamiento normativo es a la constatación de que existen normas con una fuerte carga de arbitrariedad, frente a otras, que pueden explicarse con argumentos gramaticales. Entre las primeras, cabe señalar las construcciones deber + infinitivo y deber de + infinitivo. En efecto, la RAE entiende que la primera perífrasis (sin la preposición de) debe significar 'duda, presunción o sospecha' ${ }^{1}$. Sin embargo, esta diferen-

I RAE, Gramática de la lengua española (Nueva edición, refornada, de 1931), Madrid, 1962, pág. 50.

RFE, LXXXV, 2005, 1. págs. 61-79 
cia no se justifica ni desde el propio sistema (no se ve por qué con la preposición debe significar una cosa, y otra sin la preposición), ni históricamente, pues ya en el Esbozo de una nueva gramática de la lengua española se dice textualmente: «En la lengua clásica se encuentran ya ejemplos de confusión entre deber de y deber seguido del infinitivo sin preposición; en la actualidad la confusión es muy frecuente en el habla corriente oral y escrita. En la lengua literaria se mantiene más clara la diferencia entre deber de (suposición) y deber (estar obligado) [...]. La diferencia es muy expresiva y la Academia recomienda mantenerla» ${ }^{2}$. Por lo tanto, da la impresión de que la norma sobre el uso de estas dos construcciones perifrásticas se apoya únicamente en la «expresividad», aunque creo que hubiera resultado más apropiado basarla en el intento de evitar ambigüedades: Pedro debe de estar en casa (= 'probablemente está en casa') y Pedro debe estar en casa (= 'está obligado a estar en casa'). La confusión histórica entre las dos construcciones que comentamos se desprende de los muchos ejemplos que aporta R. J. Cuervo en la entrada léxica 'deber' de su Diccionario. Así, dice: «Por analogía con haber de, se halla á cada paso en nuestros autores deber de, en el sentido de obligación, necesidad, lo cual se mira hoy como incorrecto [...] ${ }^{3}$. Y añade más adelante: «Los gramáticos asientan la diferencia entre 'Juan debe estar agradecido' (tiene obligación) y 'Juan debe de estar agradecido' (es probable que esté). Aunque el uso no siempre ha observado esta delicadeza, que no se funda por otra parte en el valor de los términos, es patente la tendencia a distinguir las dos construcciones y se debe sin duda contribuir á apoyarla en el sentido en que lo dicen los preceptistas» ${ }^{4}$. Y aporta un buen puñado de ejemplos con deber en lugar de deber de. Parece, pues, claro que la norma que rige actualmente sobre la diferenciación de ambas perífrasis no se justifica desde el sistema, sino que se impone por el deseo de evitar posibles ambiguiedades.

De la misma manera, también parece arbitraria la norma por la que la RAE, siguiendo a Bello ${ }^{5}$, condena el uso del gerundio con valor de posterioridad en relación con el verbo del que depende: «Con esta significación [temporal] denota el gerundio simple coincidencia de tiempo o tiempo inmediatamente anterior, nunca posterion ${ }^{6}$. No se alcanza a entender por qué la acción del gerundio puede ser anterior a la del verbo principal y no posterior. En el Esbozo de

\footnotetext{
${ }^{2} \mathrm{RAE}$, Esbozo de una nueva gramática de la lengua española, Madrid, Espasa Calpe, 1973, pág. 448.

${ }^{3}$ R. J. Cuervo, Diccionario de construcción y régimen de la lengua castellana, Bogotá, Ins" tituto Caro y Cuervo, 1954, t. II, pág. 807.

${ }^{4}$ R. J. Cuervo, op. cit., 1954, pág. 808

5 Andrés Bello, Gramática de la lengua castellana, edición corregida y aumentada con un prólogo y notas de Niceto Alcalá-Zamora y Torres, $8^{a}$ ed. Sopena, Argentina, 1970, pág. 162.

${ }^{6} \mathrm{RAE}$, op. cit., 1962, pág. 415.
} 
una nueva gramática de la lengua española, se justifica el valor temporal de posterioridad del gerundio siempre que ésta sea inmediata: «Salió de la estancia dando un fuerte portazo» ${ }^{7}$, pero se considera incorrecta si la posterioridad no es inmediata. Esto es lo que afirma también M. Seco en su Diccionario de dudas: «Cuando el gerundio [...] expresa tiempo, puede enunciar acción simultánea a la del verbo principal [...]; o inmediatamente anterior[...]; o inmediatamente posterior [...]. Este gerundio de posterioridad no es considerado correcto por los gramáticos, pero lo es cuando la posterioridad es inmediata a la acción principal» ${ }^{8}$. Pero ¿cómo se mide la inmediatez? Por otro lado, son legión los textos con gerundios de posterioridad en todas las épocas del español, incluida la actual. He aquí un texto reciente aparecido en un Organismo público: «Por razones de seguridad, el Centro estará abierto solo hasta las 19,30 horas, cerrándose a partir de esa hora». Este tipo de textos abundan en las páginas de escritores de reconocido prestigio. De hecho, ya Niceto Alcalá-Zamora y Torres justifica en una observación en la Gramática de Bello, frente a lo que éste expresa, los usos del gerundio con «efectos, resultados, o consecuencias», lo que ilustra con ejemplos del Quijote, de Santa Teresa, de Gracián, del Poema de Mío Cid, de la Partida II y de Campoamor ${ }^{9}$. Pues bien, si el gerundio de posterioridad no inmediata ha sido y es frecuente, incluso en textos cultos, su condena puede responder más al efecto de «estilo poco elegante» que a su naturaleza gramatical. Dicho de otra manera: no hay nada en el gerundio que impida su empleo con valor de posterioridad inmediata o mediata. La norma, pues, es arbitraria, aunque debamos acatarla tan solo sea por el prurito de elegancia estilística.

De la misma manera, presentan una fuerte carga de arbitrariedad normas como la que exige escribir en una sola palabra las formas decimotercero, decimocuarto..., y en dos los ordinales compuestos a partir de «veinte», como vigésima segunda, trigésima tercera, etc., cuando parece claro que morfológica y prosódicamente se trata del mismo fenómeno. De hecho, la pronunciación tónica del primer componente resulta forzada. Lo mismo ocurre con la norma que exige decir duodécimo y undécimo frente a las formas consideradas incorrectas *decimosegundo y *decimoprimero respectivamente. Es bien sabido que la analogía explica, y justifica con frecuencia, muchos fenómenos en linguística, de modo que si decimos decimotercero, decimocuarto, etc., nada debería impedir que, al lado de undécimo y duodécimo, pudiéramos emplear las formas decimoprimero y decimosegundo, formas que, por otra parte, están suficiente-

\footnotetext{
${ }^{7}$ RAE, op. cit., 1973, pág. 488.

${ }^{8}$ Manuei Seco, Diccionario de dudas y dificultades de la lengua española, Madrid, Espasa Calpe, 1998, $10^{2}$ ed., pág. 227.

${ }^{9}$ A. Bello y R. J. Cuervo, op. cit., 1970, pág. 167.
} 
mente documentadas en textos cultos. También cabría preguntar por qué se recomienda decir veintiún mil personas (en vez de veintiuna mil personas), cuarenta y un mil pesetas (en vez de cuarenta y una mil pesetas). El argumento de que el primer cardinal debe concordar con mil y no con el sustantivo femenino no parece muy sólido, cuando con los cardinales doscientos, trescientos, etc., decimos doscientas (trescientas) mil personas y no *doscientos (trescientos) mil personas. Si a ello se añade que la concordancia con el sustantivo femenino y no con el cardinal mil está boy muy extendida en el uso (antes lo normal era la concordancia con mil), no parece justificada la condena de la concordancia con el sustantivo ${ }^{10}$. Es por otra parte más coherente sintácticamente una combinación como veintiuna mil setecientas personas que veintiún mil setecientas personas.

Arbitrariedad había también en la consideración como defectivos de los verbos agredir y transgredir. Con buen criterio, la RAE ya los considera verbos plenos por primera vez en su Diccionario de 2001. Nada había en la gramática de estos verbos que impidiera su uso en las formas de la conjugación en que no apareciera la vocal temática -i-. Quizá la Academia deba plantearse también la posibilidad de que el verbo abolir pueda usarse como verbo pleno. Documentos hay, aunque todavía pocos, de formas como abole $(n)$ y abola $(n)$.

Muchos ejemplos más podríamos añadir en relación con la arbitrariedad (tantas veces aparente) de algunas otras normas. Pero lo que en este trabajo nos interesa, sobre todas las cosas, es la comprobación de que plantearse cuestiones normativa suele llevarnos a descubrir reglas que dentro o fuera del sistema linguístico justifican unas veces la condena de fenómenos linguísticos, pero otras veces pueden al menos explicar, si no justificar, las presuntas incorrecciones. $\mathrm{Y}$ en ocasiones podemos plantearnos dudas sobre ciertos comportamientos normativos acerca de los que la RAE no se ha pronunciado. Parece, pues, interesante bucear por aspectos normativos con el fin de llegar más lejos en la reflexión gramatical. Para ello, comentaremos unas pocas cuestiones pertenecientes a los diferentes planos lingüísticos.

\section{Plano FóniCo-GRÁFico}

Sin avisar de manera explícita, que yo sepa, la RAE ha cambiado la acentuación de las palabras tedeum y mildéu en su última edición del DRAE (la de 2201) con relación a ediciones anteriores, incluida la de 1992. En efecto, la

${ }^{10}$ No debe confundirse el uso de veintiún, treinta y un, etc., delante del cardinal mil precediendo a un sustantivo femenino, con el uso de esos cardinales delante del sustantivo (sin el cardinal mil). En este caso, la noma obliga a que la concordancia sea en femenino: veintiuna personas, y no *veintiún personas. 
palabra hoy escrita como tedeum aparecía antes como tedéum (con tilde en la -e-); y mildéu aparecía antes como mildeu (sin tilde en la -e-). La obligación de un linguiista es preguntarse el porqué de estos cambios que, como se ve, afectan a dos palabras que acaban con la secuencia vocálica -eu-. Da la impresión de que estas palabras fueron consideradas llanas y trisílabas hasta la publicación de la última edición del DRAE; es decir, su 'silabación' sería la de te-de-um y milde $u$ respectivamente. De esta manera, la tilde en -é- de tedéum se justificaba por tratarse de una palabra llana acabada en $-\mathrm{m}$, mientras que la ausencia de la tilde en mildeu se debía a que ésta era palabra llana acabada en vocal. Sin embargo, en la Ortografía académica de 1999 se considera diptongo «a efectos ortográficos» ${ }^{11}$ toda combinación de vocal abierta seguida de vocal cerrada «siempre que la cerrada no sea tónica» ${ }^{12}$. Con esta doctrina, parece claro que tedeum y mildéu son palabras bisílabas y, por tanto, agudas, lo que ha provocado los cambios de acentuación mencionados ${ }^{13}$. Ahora bien, la obligación del lingüista va todavía más lejos en su investigación: ¿Por qué la RAE pasa a tratar como agudas palabras que antes consideró llanas? Obsérvese que la doctrina sobre la configuración de los diptongos vertida en la Ortografia de 1999 dice claramente «a efectos ortográficos». Pareciera que con ello la RAE no está segura de que las combinaciones vocálicas como las que se dan en las palabras que comentamos constituyan diptongos auténticos en el plano fónico. $\mathrm{Y}$ algo de eso debe de ocurrir, pues las respuestas que yo he requerido a informantes cultos, la mayoría filólogos (alumnos universitario y profesores de Enseñanza Secundaria y de universidad), no coincidían a la hora de señalar el número de sílabas en las palabras tedeum y mildéu (para unos, tres silabas; para otros, dos silabas; y un buen porcentaje de informantes no se pronunciaba por no tener criterio claro). ¿Qué quiere decir esto? Sin duda, que la frontera entre el diptongo y el hiato no siempre es nítida; que posiblemente unos perciban hiato y otros diptongo en relación con su procedencia geográfica o con el registro donde puedan pronunciar estas palabras. No deja de ser curioso que todos mis informantes coincidían en que las combinaciones - $a u$, -eu- en palabras como farmacéutico o cáustico eran claros diptongos. Parece, pues, que la vacilación se produce exclusivamente cuando tales combinaciones aparecen en posición final de palabra. ¿Cuál es la causa de que así sea? Necesitamos, sin duda, trabajos experimentales que arrojen más luz sobre la naturaleza fónica de ciertas combinaciones vocálicas cuya frontera entre el diptongo y el hiato es borrosa.

\footnotetext{
1 RAE, Ortografía de la lengua española, Madrid, Espasa Calpe, 1999, pág. 43

12 RAE, ibídem.

${ }^{13}$ Era evidente la contradicción en el DRAE de 1992 entre las palabras mildeu (sic) y marramáu, pues ésta aparecía con tilde (como ahora mildéu) y aquélla sin la tilde, cuando es claro que se trata del mismo fenómeno fónico-gráfico.
} 
Otro cambio de acentuación reciente se ha producido en las palabras chiita y chiismo. Estas dos palabras se registran por primera vez en el DRAE de 1992 y con tilde en la segunda -i- (chiita, chiísmo). Posteriormente, en la Ortografia académica de 1999 aparece la palabra chiita, sin tilde, como uno de los ejemplos de hiatos con dos vocales iguales seguidas ${ }^{14}$. Esta forma no acentuada se confirma en el DRAE de 2001, junto con la palabra chiismo, que aparece también sin tilde. Es, pues, evidente que la RAE ha cambiado el criterio de acentuación de estas palabras y, en consecuencia, de otras del mismo tenor como Rociito, friito, litto, diita, tiito-a, priista y priismo ${ }^{15}$, etc., que responden a la misma configuración voćlica y que no se incluyen en el DRAE por razones obvias. La pregunta del lingüista una vez más es obligada: ¿Por qué ese cambio de criterio en unos pocos años? Aunque la RAE, otra vez, registra el cambio sin aviso explícito, como a escondidas, parece que este se debe a que en un principio se quería marcar el hiato con la tilde (-i-í-), y que posteriormente los académicos se percataron de que con la tilde en estas palabras conculcaban una de las reglas de acentuación más firmes: que aquella tilde cuya misión es simplemente la de marcar un hiato sólo es posible si con ella se evita un posible diptongo ( $b a-u ́ l$, para que no se pronuncie $b a u l$; gui-a para que no se pronuncie guia, etc.). Y es evidente que la tilde que marcaba los hiatos de chitta y chiismo era innecesaria por cuanto nunca la combinación -ii- podría pronunciarse como diptongo, por la sencilla razón de que en español no hay diptongos de este tipo. Sin embargo, es posible que la acentuación de chiita y chiismo (y, por tanto, de Rociito, tiito-a, etc.) tuviera su utilidad en la medida en que se evitaría una pronunciación con reducción de las dos íes a una sola ${ }^{16}$. De hecho, lo normal en la prensa española actual es escribir Rocitito (con tilde) y no Rociito (sin tilde), a pesar de lo que se desprende de la escritura en el DRAE de 2001 de chita y chismo.

Existe una gran vacilación a la hora de acentuar o no algunos pronombres o adverbios como quien(es), que, (a)donde, como, cual(es), precedidos o no de preposición, cuando se encuentran dentro de una oración subordinada de infinitivo y ésta depende de verbos como tener, haber, buscar o encontrar. Son casos como los siguientes:

- No tiene (a)donde/ (a)dónde ir

- No hay donde/dónde caerse muerto

- No tenemos a quien/a quién acudir

- No tenemos (no hay) como/cómo hacerlo

\footnotetext{
${ }^{14}$ RAE, op. cit., 1999, pág. 45.

${ }^{15}$ El DRAE no registra priista ni prismo, pero son frecuentes en la prensa cuando ser refieren al PRI mexicano.

${ }^{16}$ Observese que en el lenguaje infantil es normal la reducción en tito-a (de tito-a).
} 
- No tengo (no hay) de que/de qué hablar

- Andaba buscando a quien/a quién dirigir el balón

- No encuentra como/cómo resolver el problema

Hay que decir, en primer lugar, que la Ortografía académica no dice nada al respecto; y, en segundo lugar, que los datos que ofrecen los corpus CORDE (Corpus Diacrónico del Español) y CREA (Corpus de Referencia del Español Actual) de la RAE arrojan unos resultados muy similares de acentuación y de no acentuación de esos pronombres y adverbios. Por tanto, parece clara la vacilación, por lo que la RAE debería dar una respuesta a este problema ${ }^{17}$. El lingüista debe preguntarse el porqué de tal vacilación, $o$, lo que es lo mismo, cuál es la naturaleza gramatical de dichos pronombres y adverbios. ¿Son interrogativos? No parece fácilmente asumible que estemos ante oraciones interrogativas indirectas, pues los verbos tener, haber, buscar o encontrar no presentan los rasgos propios de las palabras introductoras de tales interrogativas, pues no pertenecen a los campos del 'decir', del 'sentir' o del 'pensar', que son las que normalmente están capacitadas para introducir ese tipo de oraciones. Además, no podríamos explicar por qué en un enunciado como No tengo quien me ayude la subordinada es de relativo, y en otro como No tengo a quien/quién ayudar la subordinada tuviera que ser interrogativa. La solución, come se ve, no es fácil, ya que por un lado parece que los pronombre y adverbios mencionados son relativos, por lo que no deberían llevar tilde, pero por otro tienden a pronunciarse tónicos, por lo que posiblemente la tilde diacrítica sería necesaria en la medida en que habría que diferenciar relativos átonos de sus homónimos tónicos. La conversión de un relativo átono en un relativo tónico se produce cuando desaparece un antecedente sin determinante y de carácter general como nada, nadie, persona(s), cosa(s), sitio (lugar), forma (manera), que podríamos recuperar en cualquier momento:

- No tengo nada de que hablar $\rightarrow$ No tengo de que/de qué hablar

- No tenemos (no hay) sitio donde caemos muertos $\rightarrow$ No tenemos (no hay) donde/dónde caernos muertos

- No encuentro la forma como hacerlo $\rightarrow$ No encuentro como/cómo hacerlo

- No hay persona a quien acudir $\rightarrow$ No hay a quien/a quién acudir.

Obsérvese que, cuando estos pronombres y adverbios son interrogativos, no llevan este tipo de antecedente, pero sí pueden llevar en algunos casos un consecuente:

\footnotetext{
17 La RAE en su última Ortografía dice de estas palabras: «Cuando reside en ellas el sentido interrogativo o exclamativo [...] son tónicas y llevan tilde", y a continuación aparecen ejemplos donde las oraciones en que se insertan son claramente interrogativas o exclamativas indirectas; no se ofrece ni un solo ejempio con los verbos que aquí nos interesan; vid. RAE, op. cit., 1999, pág. 50.
} 
_- *No sé casa a la que ir (adonde ir)/No sé a qué casa ir (frente a: No tengo casa a la que ir $/ *$ No tengo a qué casa ir.

- *Preguntó cosas que comíamos/Preguntó qué cosas comíamos (frente a: No tenemos cosas que comer $/ *$ No tenemos qué cosas comer.

Por otro lado, se dan correspondencias entre oraciones con un sintagma nominal que incluye una oración de relativo con antecedente y una oración interrogativa indirecta en la que el interrogativo se puede acompañar del consecuente, que es el mismo que el antecedente. Ello es imposible en las oraciones que nos ocupan aquí:

- Pregúntale la hora que es $\rightarrow$ Pregúntale qué hora es (frente a: *No tengo el coche que conducir; *No tengo qué coche conducir).

Resumiendo, parece claro que tras una cuestión normativa se esconden problemas de gran calado gramatical, hasta el punto de plantearnos si los pronombres y adverbios mencionados en las estructuras también mencionadas, son relativos o interrogativos; y si, como parece, son relativos, por qué tienden a ser tónicos. Es más, quizá cupiera también preguntarse si no hay grados de 'tonicidad' en estas palabras en función de algunos factores. Así, parecen más tónicos cuando van precedidos de preposición. En efecto, resulta forzada la pronunciación átona de donde en No tengo por donde/dónde ir mientras que se puede pronunciar átono o tónico, sin que ello suponga violencia alguna, en $N o$ tengo donde/dónde caerme muerto. También parece más tónico el pronombre o adverbio si el infinitivo no va acompañado de complemento alguno que si va acompañado. Compárense: No tenemos a quien/quién entregar este ramo de flores y No tenemos a quién/quien acudir. Añádase a todo ello que cuando el pronombre relativo que podría entrar en conflicto con la conjunción homónima, debe pronunciarse siempre tónico para evitar una posible ambigüedad: No tengo que comer/No tengo qué comer. Está claro que si en este último caso ponemos la tilde en el relativo, que es obligatoriamente tónico, no se ve la razón por la que no haya que ponérsela a los demás pronombres y adverbios relativos, más tónicos que átonos, a los que me vengo refiriendo. Otro caso de posible ambigüedad entre el relativo como/cómo y el no relativo homónimo podría ser el siguiente: No hay como/cómo salir de aquí/No hay como salir de aquí (=salir de aquí es lo mejor). Por tanto, el hecho de que tales pronombres y adverbios en las estructuras comentadas puedan evitar ambigüedades en unos casos y el que suelan pronunciarse tónicos, aunque con distintos grados de 'tonicidad', invita a aconsejar ponerles la tilde siempre.

Tampoco la RAE se pronuncia clara y explícitamente sobre si hay que acentuar las palabras quien(es) y cual(es) cuando aparecen al final de enunciados del tipo siguiente: 
- Hay que saber quién es quien/quién

- Hay que saber cuál es cual/cuál.

Si nos atenemos al hecho de que en estos enunciados las formas en cursiva quien(es) y cual(es) son indefinidos y no interrogativos (equivalen a 'cada uno' ('cada cual'), 'cada cosa', respectivamente), no habría que ponerles tilde, pues la RAE no dice en su última Ortografia que un indefinido tenga que llevar tilde diacrítica. Ahora bien, como, tal y como se dijo más arriba, la RAE habla de "sentido interrogativo o exclamativo" para justificar la tilde de palabras como quien, cual, entre otras ${ }^{18}$, nada impediría la tilde en tales formas, pues se trata de indefinidos procedentes de interrogativos y, por tanto, de alguna manera mantienen «sentido» interrogativo. Por otro lado, son formas tónicas aunque solo sea por el hecho de ocupar el último lugar del enunciado. Por estas razones, yo me inclinaría por marcar con tilde tales formas. De hecho, los datos del CREA y del CORDE son los siguientes, favorables, como se ve, a la tilde:

- Quién es quién. (Alrededor de 55 casos en CREA y de 25 en CORDE.)

- Quién es quien. ( 3 casos en CREA y 1 en CORDE.)

- Cuál es cuál. (13 casos en CREA y ninguno en CORDE.)

- Cuál es cual. ( 2 casos en CREA y ninguno en CORDE.)

Una vez más vemos que tras una cuestión normativa se plantea el problema de la naturaleza gramatical y prosódica de los elementos que analizamos.

La RAE tampoco dice nada sobre la acentuación o no acentuación de la palabra quien(es) con el significado de 'nadie' y, por tanto, con valor funcional de indefinido, en enunciados del tipo siguiente:

-Tú no eres quien/quién para opinar

-No sois quienes/quiénes para decir eso.

También en este caso estamos ante una palabra que no funciona como un interogativo, por lo que la tilde no parecería obligada; sin embargo, su «sentido» interrogativo (procede de ¿Quién eres tú para...?; ¿Quiénes sois vosotros para...?) y su carácter tónico exigen la tilde. La RAE en su DRAE registra la construcción no ser alguien $\sim$, donde el signo $\sim$ representa a quien, que se encuentra en la acepción 5 como pronombre indefinido, por lo que al no aparecer la palabra en cuestión nos quedamos con la duda de si habría que ponerle o no la tilde ${ }^{19}$. Manuel

\footnotetext{
${ }^{18}$ RAE, op. cit., 1999, pág. 50. Precisamente, el «sentido» interrogativo justificaría la tilde en las formas donde, cuando, como, quien, que, cuando son sustantivos: No se ha fjado aún el dónde ni el cuándo de la proxima reunión; Lo que importa es el qué y no el cuándo ni el quién.

${ }^{19}$ El DRAE no registra las formas quien/quién como entradas léxicas diferentes, frente a lo que hacen otros diccionarios, sino como una única entrada, donde se dan los valores diversos gramaticales de pronombre relativo, pronombre interrogativo y pronombre indefinido. No obstante, deducimos que la palabra quién en la expresión mencionada llevaría tilde si se hubiera ex-
} 
Seco, en su Diccionario de dudas, la da acentuada: «No soy quién para opinar al respectos ${ }^{20}$.

También en el ejemplo que aporta en su Diccionario del Español Actual, la palabra quien como indefinido con el significado de 'nadie' aparece con til$\mathrm{de}^{21}$. Por su parte, el CREA arroja los siguientes resultados:

$$
\begin{array}{ll}
\text { - Eres quién para... } & \text { (5 casos.) } \\
\text { - Eres quien para... } & \text { (1 caso.) } \\
\text { - Es quién para.... } & \text { (17 casos.) } \\
\text { - Es quien para... } & \text { (2 casos.) }
\end{array}
$$

Parece claro, pues, que la RAE debería decir en su Ortografía que la forma quien como pronombre indefinido debería tildarse. En cualquier caso, se trata de un fenómeno normativo que obliga a la reflexión gramatical: la posible gramaticalización de un interrogativo hacia un valor indefinido y sus consecuencias ortográficas.

Un último caso del valor indefinido en quien es el que aparece en la correlación indefinida quien/quién más quien/quién menos (= "unos más, otros menos'). Manuel Seco, en su Diccionario de dudas ${ }^{22}$ y en el Diccionario del Español Actual ${ }^{23}$ da como válidas las formas quienqquién de esta locución (con tilde y sin tilde); en el primer caso, porque la pronunciación es normalmente átona. En el Diccionario de María Moliner, aparecen exclusivamente sin tilde $^{24}$. Por su parte, el CREA y el CORDE arrojan los siguientes resultados:

$$
\begin{array}{ll}
\text { - quien más quien menos. } & \text { (39 casos en CREA; } 13 \text { en CORDE.) } \\
\text { - quién más quién menos. } & \text { (10 casos en CREA; } 7 \text { en CORDE.) }
\end{array}
$$

Es, pues, mayoritaria la ausencia de la tilde en estas formas, por lo que se da a entender que se pronuncian más frecuentemente como átonas. En cualquier caso, estamos una vez más ante una cuestión de naturaleza gramatical, prosódica y ortográfica vacilante.

Como es sabido, la palabra como se pronuncia átona cuando es adverbio relativo o cuando es conjunción modal, comparativa, causal o condicional; y se pronuncia tónica cuando es adverbio interrogativo o exclamativo; en este caso, se escribe con tilde diacrítica. Pero existe un como del que nada dice la Orto-

\footnotetext{
plicitado, pues entiendo que, al aparecer en una acepción en la que se habla de las formas quiénes... quiénes con valor indefinido y con tilde, también debe llevarla la otra forma indefinida.

${ }^{20}$ Manuel Seco, op. cit., 1998, pág. 377.

21 Manuel Seco; Olimpia Andrés; Gabino Ramos, Diccionario del Español Actual, Madrid, Aguilar, 1999.

${ }^{22}$ Manuel Seco, op. cit., 1998, pág. 378

${ }^{23}$ Manuel Seco; Olimpia Andrés; Gabino Ramos, op. cit., 1999.

${ }^{24}$ María Moliner, Diccionario de uso del español, $2^{a}$ ed. Madrid, Gredos, 1998.
} 
grafía académica de 1999; me refiero a cuando funciona como conjunción completiva, más o menos equivalente a la conjunción subordinante que; en este caso, se tiende a pronunciar tónico, por lo que una vez más surgen las dudas sobre su acentuación: como conjunción no debería llevar tilde (ninguna conjunción es tónica), pero su «tonicidad» podría requerirla. Se da en casos como los siguientes:

- Ya verás como/cómo no llegamos a tiempo al estadio

- Ya has visto como/cómo me he callado para no meter la pata.

La pregunta es obligada: $i$ debe llevar tilde esta forma por ser tónica, o se debe prescindir de ella porque es una conjunción? En la Gramática de la RAE, los ejemplos que se ofrecen presentan esta forma sin tilde ${ }^{25}$. Manuel Seco, por su parte, aunque trata esta conjunción dentro de la entrada léxica correspondiente sin tilde, advierte que «es muy frecuente la pronunciación tónica» ${ }^{26}$, por lo que parece estar de acuerdo con R. J. Cúrvo, quien acentúa todos los como de este tipo ${ }^{27}$. En el Diccionario de María Moliner, sin embargo, los ejemplos se dan sin tilde ${ }^{28}$. En el CREA la documentación de esta forma con tilde y sin tilde es muy pareja, lo que indica la gran vacilación al respecto. En mi opinión, no debería llevar tilde sin nos atenemos a los argumentos siguientes: Conviene diferenciar pares de oraciones que significan de forma distinta con el adverbio cómo y con la conjunción que comentamos:

- Ya verá cómo habla Juan (= «su forma de hablar»)/Ya verás como habla Juan (= «...que Juan habla»).

De ejemplos como los expuestos parece deducirse que el grado de 'tonicidad' de esta conjunción como es menor o menos intenso que el del adverbio interrogativo, hasta parecer que se pronuncia o que puede pronunciarse átono.

No obstante, el problema se agrava cuando nos percatamos de que no son infrecuentes los enunciados en que la palabra como parece aglutinar los valores de conjunción completiva y de adverbio interrogativo. Obsérvense los ejemplos siguientes:

- En ese momento sentí como/cómo alguien me golpeaba la espalda

- Juan se dio cuenta perfectamente de como/cómo se cerraba tras él la * puerta de su despacho.

En estos casos, debería proponerse la doble opción (tildar la palabra o no tildarla), pero advirtiendo que con la tilde se potencia más el valor interro-

\footnotetext{
${ }^{25}$ RAE, op. cit., 1962, pág. 337.

${ }^{26}$ Manuel Seco, op. cit., 1998, pág. 117

${ }^{27}$ Rufino José Cuervo, op. cit., 1954, pág. 241 (t. II).

${ }^{28}$ María Moliner, op. cit., 1998.
} 
gativo, y sin la tilde el valor conjuntivo. Como se ve, una vez más tras una cuestión normativa se esconden problemas gramaticales y prosódicos de sumo interés.

\section{Plano morfológico}

De los muchos fenómenos morfológicos que plantean o pueden plantear dudas normativas y que invitan claramente a una reflexión gramatical de cierto calado, selecciono para este trabajo sólo tres, que, en mi opinión, resultan reveladores. Aunque la RAE en su Ortografia de 1999 no dice nada sobre la manera de escribir los prefijos respecto de la base léxica a la que se adhieren, parece deducirse del DRAE de 2001 que deben escribirse en una sola palabra y no en dos ni en una con guion de separación. En efecto, en esta última obra encontramos (unas veces dentro del prefijo como entrada léxica, y otras con la palabra prefijada como entrada autónoma) palabras como superhombre, superdotado, superelegante, antiacadémico, contraatacar, contraconcepción, contracultura, posmoderno, postónico, etc.; es decir, sin guion entre el prefijo y su base léxica, y sin separación de los componentes de las palabras prefijadas. Sin embargo, con ex se hace una excepción, pues en el DRAE de 2001 se escribe ex ministro y ex marido, es decir, en dos palabras. Está claro que un gramático debe reflexionar sobre esta cuestión y tratar de responder a varias preguntas como: ¿por qué $e x$ resulta una excepción? ¿Es arbitrario o no este comportamiento gráfico? Obsérvese que ya en ediciones anteriores del DRAE aparecían las formas ex provincial, ex ministro, ex discípulo y ex monárquico, también en dos palabras. En esas ediciones parecía justificar la RAE este tipo de escritura por entender que ex no era en esos casos un prefijo sino una preposición, pero no parecía un argumento sólido por cuanto otros muchos también podrían considerarse preposiciones, pues lo eran en latín, al igual que ex, o lo son en castellano, como contra en contracultura. Si nos fijamos en la edición de 2001, la RAE entiende ahora que esa forma ex de ex ministro, ex marido, etc., es un adjetivo. Se trata, pues, de un cambio muy importante en la concepción gramatical de este elemento. Está claro que si $e x$ es un adjetivo debe escribirse como palabra autónoma. La naturaleza adjetival parece venir avalada por que puede sustituirse por el adjetivo antiguo (mi ex marido $=$ mi antiguo marido) y por la facilidad con que se sustantiva: mi ex; un ex del colegio; el ex de Marta... En este aspecto, la forma ex va más lejos que su sinónimo antiguo- $a$, ya que este adjetivo no se sustantiva con la misma facilidad: *mi antiguo; *un antiguo del colegio; *el antiguo de Marta. Ahora bien, si ex es un adjetivo habría que preguntar por qué no admite, al ser palabra aguda $\mathrm{y}$ acabada en - $\mathrm{x}$, desinencia de número, ya que no se dice *los exes, sino los ex (frente a, por 
ejemplo, los faxes). Parece, pues, un adjetivo peculiar, incluso si nos percatamos de que solo admite anteposición y nunca posposición. Posiblemente se trate de una forma híbrida, con rasgos de adjetivo y con rasgos todavía de prefi$\mathrm{jo}^{29}$. Es posible que la naturaleza adjetival o cuasiadjetival y la capacidad de sustantivación de esta forma ex justifiquen su escritura como palabra autónoma. Pero cabe añadir algunos argumentos más a favor de esta forma de escritura: la tendencia a pronunciarse tónica la forma ex en las estructuras que comentamos, sin que ello suponga ninguna violencia prosódica ni una necesidad enfática; así, no es raro oír [mi éx marído], [su éx ekípo], al lado de pronunciaciones átonas, cada vez menos frecuentes. Ningún otro prefijo soportaría la pronunciación tónica, salvo por necesidades de énfasis como en [ún súperekípo]. Por otra parte, ex es perfectamente compatible con algunos otros prefijos como en ex vicerrector, ex multimillonario, ex proetarra, ex contrarrevolucionario, [un] ex antidisturbios, etc. Esta compatibilidad entre prefijos es rara ${ }^{30}$. Además, la forma $e x$ se combina fácilmente con compuestos sintácticos como en ex alto cargo, ex guardia civil, ex primera dama, ex primer ministro, ex número 1 del mundo, etc., en los que por razones obvias no podría adherirse al primer componente del compuesto. Añádase a estos argumentos la facilidad que tiene $e x$ de llevar complementos nominales con de cuando se sustantiva: un ex del equipo, el ex de Marta, etc. Por tanto, el que la palabra ex se escriba separada de la palabra a la que modifica no parece arbitrario, sino que responde a su peculiar conformación gramatical. Otra cosa es el uso de ex con adjetivos (salvo que estén sustantivados); en este caso, sigue siendo prefijo, por lo que debe escribirse adherido a su base léxica: un país exsoviético (no *ex soviético, a pesar de que aparece escrito así con frecuencia). Los argumentos esgrimidos anteriormente para separar $e x$ del sustantivo no valen cuando se trata de unirlo a adjetivos.

Otro fenómeno morfológico que ha merecido mi atención es el de las concordancias del sustantivo azúcar con el determinativo artículo y con los adjetivos que lo modifican. En efecto, dicho sustantivo aparece en el DRAE como ambiguo en cuanto al género; de ahí que sean igualmente correctas las combinaciones del tipo azúcar moreno y azúcar morena; pero lo que sorprende es que el artículo pueda adoptar, o tienda a adoptar en la actualidad, al menos en España ${ }^{31}$, la

\footnotetext{
${ }^{29}$ Algunos otros adjetivos como mero-a presentan esta misma característica: un mero trímite (*un trámite mero).

${ }^{30}$ También super parece presentar esta característica: super vicerrector (mejor que supervicerrector), lo que debería aconsejar su escritura separada del resto de la palabra ya prefijada. Además, en ejemplos como éste también es tónica la pronunciación de super. Pienso que habrá que estudiar con más detenimiento los rasgos gramaticales y prosódicos de este prefijo (también de híper- y pro-) en el español actual.

${ }^{31}$ En CORDE se registran 40 casos de la azúcar, de los que solo 5 son españoles. En CREA se registran 14 casos de la azúcar, todos ellos en América.
} 
forma $e l$ con adjetivos en su forma femenina: el azúcar moreno al lado de $e l$ azúcar morena. Esto no ocurre con ningún otro sustantivo que la Academia considere ambiguo, pues decimos el mar tranquilo o la mar tranquila, pero no ${ }^{*}$ el mar tranquila. Está claro que tras esta cuestión normativa se esconde un problema gramatical del que no se ha hablado (hasta donde a mí se me alcanza). La explicación que se me ocurre para justificar este comportamiento aparentemente anómalo en la concordancia es la de considerar que se trata de un resto del artículo femenino (que no masculino) $e l$ delante de a- inicial átona, lo que no era raro en épocas pasadas (en el Romancero aparece: «El Alhambra era, señor»). He detectado este mismo uso con las palabras arroz y aceite, que, curiosamente, pertenecen también al campo semántico de la «comida». Bien es verdad que con estas palabras el uso de $e l$ y adjetivo en femenino presenta carácter dialectal y/o popular. Lo he oído en zonas de León, Zamora y Salamanca: El arroz está pasada; El aceite está quemada ${ }^{32}$.

Por último, no es fácil percatarse de la incorrección que se da en el sintagma * el alma máter. Está claro que debe decirse la alma máter, forma que se oye y se escribe con menos frecuencia que la forma incorrecta. El gramático debe saber que el artículo en esta expresión es la y no $e l$, ya que debe concordar con el sustantivo máter, que en latín era femenino. Quienes escriben o dicen * el alma máter lo hacen creyendo que alma es sustantivo, cuando, como se sabe, es el adjetivo femenino latino que significa 'nutricia'. Como la forma de artículo $e l$ sólo rige para sustantivos femeninos que empiezan por a- tónica y no para adjetivos, debe decirse la alma máter, como decimos la árida estepa o la áspera corteza; y, por supuesto, nuestra alma máter, esta alma máter, etc. Por la misma razón, se deberá decir y escribir la áurea mediócritas y no *el áurea mediócritas, pues áurea es adjetivo ${ }^{33}$. Otra cosa es que la RAE tenga en cuenta exclusivamente el uso mayoritario y nos sorprenda algún día con el reconocimiento normativo de *el alma máter ${ }^{34} \mathrm{y} *$ el áurea mediócritas.

\footnotetext{
32 Éste es un documento escrito encontrado en Intemet, referido a la zona zamorana de Aliste: «[...]el recoger envases como puede ser el caso de los fungicidas o herbicidas utilizados por los agricultores y ganaderos o el aceite quemada».

${ }^{33}$ Aunque se trata de palabras latinas que no figuran en el DRAE, prefiero acentuarlas, pues en este Diccionario las palabras latinas que figuran en él llevan tilde cuando, según las normas que rigen para el castellano, la requieren. Entre esas palabras se registra páter como «sacerdote».

${ }^{34}$ Debido al desconocimiento de que alma en esta expresión es adjetivo y no sustantivo, se documentan formas tan disparatadas como ${ }^{*}$ El alma páter del equipo es Torres. Fernando Lázaro Carreter deja constancia de este disparate en un «dardo» titulado «Hablar versátil». Dice: «Así, consiguen que se produzcan saludables empujones de risa [...] como el dado a la audiencia por un relator al afirmar, lo juro, que Xavi es el alma mater y también el alma pater del Barçà, vid, Lázaro Carreter Fernando, El nuevo dardo en la palabra, Madrid,Aguilar, 2003, pág. 105.
} 


\section{Plano Sintáctico}

Es frecuente que a quienes nos dedicamos a pensar sobre cuestiones normativas del español se nos pregunte cuál de las dos construcciones siguientes es la correcta: Marta está loca de contenta; Marta está loca de contento. En principio, la respuesta adecuada debería inclinarse por la segunda, ya que un adjetivo (loca en este caso) sólo puede llevar complementos nominales precedidos de la preposición de, y no complementos adjetivales cuyo adjetivo, además, tenga que concordar con el sustantivo del sintagma en cuestión. Es claro, pues, que contento es en este sintagma un sustantivo, como lo son alegría, satisfacción, etc. Por eso decimos loca de alegría (de satisfacción...) y no *loca de alegre (de satisfecha...), y llena de contento y no *llena de contenta.

Sin embargo, es un hecho que en el uso general actual es mucho más frecuente oír y ver escrito loca de contenta y locas de contentas o locos de contentos. Otra vez el gramático tiene la oportunidad de preguntarse por el porqué de la extensión en el uso mayoritario de una forma que parece conculcar una regla sintáctica con una falsa concordancia. Puede ser, pienso yo, que se esté formando en el español actual, producto de una gramaticalización, una locución intensificadora con loca de, equivalente a 'muy' (Marta está loca de contenta = Marta está muy contenta), por lo que contenta como adjetivo encontraría explicación gramatical ${ }^{35}$. El proceso de este tipo de gramaticalización se desprende de los datos de estas construcciones obtenidos en CORDE y CREA:

CORDE: loca(s) de contento: 25 casos

loca(s) de contenta(s): 5 casos.

CREA: laca(s) de contento: 4 casos

Loca(s) de contenta(s): 7 casos.

Otro fenómeno normativo que tiene que ver con la concordancia es el que se da en enunciados del tipo siguiente: Tu vecina es de lo más simpático y $T u$ vecina es de lo más simpática. En un principio, la construcción correcta debería ser la primera, pues parece lógico que el adjetivo (simpático) y la forma neutra $l o$ concuerden. Sin embargo, nada impediría que también la segunda construcción se pudiera legitimar normativamente entendiendo que la secuencia de lo más, en un proceso de gramaticalización, se percibe como una locución intensificadora: Tu vecina es de lo más simpática (= '...muy simpática'). De esta manera, el adjetivo pasa a concordar con el sustantivo del sujeto, como ocurre en estructuras parecidas, aunque sin la forma lo: iMaría está de cansa-

${ }^{35}$ Locuciones intensificadoras similares de adjetivo y/o sustantivo son, entre otras, la mar de, infinidad de, tela de, mogollon de, asi de, que de. 
da...l; iEs de lista esta chica...' A favor del reconocimiento normativo de las dos construcciones se decantan los datos que se obtienen tanto del CORDE como del CREA, y que son los siguientes:

a) Con es de lo más + adjetivo no concordado con el sustantivo ${ }^{36}$ :

CORDE: 25 casos (solo 5 sin complemento)

CREA: 11 casos (solo 4 sin complemento)

b) Con es de lo más + adjetivo en singular concordado en género con el sustantivo:

\section{CORDE: 6 casos \\ CREA: 12 casos}

Como puede apreciarse, en singular domina la estructura no concordada (36 casos frente a 18). No obstante, me parece documentación suficiente para que ambas estructuras adquieran el reconocimiento normativo. Por otro lado, parece que en las tres últimas décadas ha aumentado el número de las estructuras concordadas con el sustantivo (12 casos en CREA frente a 6 en CORDE), mientras que en los textos anteriores dominaban las estructuras no concordadas con el sustantivo (25 casos en CORDE frente a 11 casos en CREA). Ello parece indicar que las estructuras del tipo La ley es de lo más clara se va imponiendo a la estructura La ley es de lo más claro. Ahora bien, conviene indicar que las formas no concordadas con el sustantivo suelen acompañarse de un complemento (una oración de relativo, un complemento nominal, un adjetivo); en estos casos, no es posible la sustitución de de lo más por 'muy', lo que obliga a un análisis sintáctico distinto:

- La raza es de lo más sano y hermoso que he conocido en España (*...muy sano y hermoso que he conocido...)

- La cerámica de la cueva es de lo más bárbaro posible (*...muy bárbaro posible)

- Cuya región es de lo más rico de toda España. (*... muy rico de toda España).

Únicamente 9 casos de los 36 registrados en CREA y CORDE aparecen sin complemento alguno, por lo que la secuencia de lo más es equivalente a 'muy'. He aquí uno de los casos:

- Por cierto, que [la romería] es de lo más entretenido y pintoresco (= ...muy entretenida y pintoresca).

\footnotetext{
${ }^{36}$ Como es natural, solo be tenido en cuenta los casos en que el adjetivo presenta dos terminaciones de género, porque únicamente con éstos se puede comprobar si hay o no concordancia de género.
} 
En lo que al plural se refiere, los datos obtenidos de CREA y CORDE son los siguientes:

a) Con son de lo más + adjetivo no concordado en género y número con el sustantivo:

CORDE: 22 casos ( 8 sin complemento)

CREA: 17 casos (15 sin complemento)

b) Con son de lo más + adjetivo concordado en género y/o número con el sustantivo ${ }^{37}$ :

\section{CORDE: 3 casos \\ CREA: 8 casos.}

Por tanto, estructuras como:

- Las puestas de sol son de lo más impresionantes

- Las alteraciones son de lo más variadas

son sensiblemente menos frecuentes que las del tipo siguiente:

- Las doctrinas sobre la voz y el silencio son de lo más dispar

- Las tarjetas que tiene son de lo más moderno.

Aun así, se aprecia por los datos ofrecidos que en el español actual es más frecuente la concordancia con el sustantivo que en épocas anteriores (8 casos en CREA frente a 3 en CORDE). No obstante, los casos de concordancia son sensiblemente menores en plural que en singular; además, en plural son muchos los casos de no concordancia con el sustantivo que aparecen sin complemento (frente a los 27 casos de un total de 36 con complemento en las estructuras en singular, en plural solo se cuentan 16 de un total de 39). Llama la atención la existencia de 1 caso, que manteniendo la concordancia con el sustantivo, aparece con complemento. Su autor es nada menos que D. Ramón Menéndez Pidal:

- Las copias de las obras manuelinas son de lo más estropeadas y varientadas que darse pueden.

Pero este ejemplo no deja de ser excepcional y contrario a la norma del español. No solemos decir *Estas obras son de lo más entretenidas que se pueden leer, y sí Estas obras son de lo más entretenido que se puede leer, o Estas obras son de lo más entretenidas (sin complemento).

37 Es evidente que si el adjetivo es de una sola teminación, la concordancia solo es posible en número; si es de dos terminaciones, la concordancia se establece con el género y el número. 
Si en este tipo de estructura interviene el verbo estar (y no ser), hay que decir que con el verbo en singular (Está de lo más + adjetivo) todos los casos que aparecen en CREA y CORDE son concordados con el sustantivo, como en el caso siguiente:

- Claudia Schiffer está de lo más activa.

Sin embargo, en plural (Están de lo más + adjetivo), de 5 casos registrados en CREA (no hay documentos en CORDE), en 2 hay concordancia y en 3 no la hay:

- Seis bellotas de Gernikako que están de lo más sanas

- Los canales de información no están de lo más expeditos,

frente a:

- Los zocos de Marrakech están de lo más surtido

- Y esas sus partes pudendas, que están de lo más limpio

- Las cartas están de lo más interesante.

Después de todo lo dicho, parece claro que los análisis sintácticos de estas construcciones han de ser diferentes: cuando el adjetivo no concuerda con el sustantivo ${ }^{38}$, el predicado nominal debe segmentarse con la preposición de seguida de la secuencia lo más + adjetivo (con o sin complemento) como término gramatical: Tu vecina es de lo más simpático. En esta secuencia lo se erige en el núcleo del sintagma y más simpático en el complemento de ese núcleo, con el adjetivo concordando con dicho núcleo. Pero si el adjetivo concuerda con el sustantivo, la secuencia de lo más debe analizarse como una locución que, como tal, es insegmentabe y que intensifica o cuantifica al adjetivo: $T u$ vecina es de lo más simpática.

No hace mucho tiempo alguien me preguntó cuál de los enunciados siguientes era el más correcto:

- Hay que reducir al máximo los peligros

- Hay que reducir al mínimo los peligros.

Esta cuestión normativa obliga a un planteamiento gramatical profundo. La respuesta es la de que ambos enunciados son igualmente correctos, pero ni su gramática ni su significado son iguales. En efecto, en el primer caso lo que se dice es que 'hay que reducir completamente (totalmente) los peligros', o sea,

${ }^{38}$ La no concordancia con el sustantivo en singular solo es posible detectarla cuando este es de género femenino; si es de género masculino, no podemos saber si nos encontramos ante una construcción en que el adjetivo concuerda con el sustantivo o con el pronombre lo: Tu vecino es de lo más simpático. 
dejarlos a cero. En el segundo caso, lo que se dice es que 'hay que reducir los peligros, de modo que éstos sean muy pocos (pero no cero)'. En cuanto a la configuración gramatical de ambas estructuras, es claro que la expresión adverbial al máximo cuantifica y complementa al verbo reducir; es un sinónimo de 'totalmente', 'completamente', etc. Sin embargo, la expresión adverbial al mínimo se comporta como una cláusula reducida, de forma que el enunciado correspondiente es parafaseable en 'Hay que reducir los peligros, de formas que éstos sean mínimos' (frente a: '*Hay que reducir los peligros, de forma que éstos sean máximos').

Estos enunciados, aparentemente sinónimos, se dan con verbos que como reducir, disminuir, restringir... significan 'gradación de arriba abajo', y no 'de abajo arriba' como ocurre con verbos del tipo aumentar, agrandar, acrecentar, etc.: Hay que aumentar al máximo todas las alarmas (frente a: "'Hay que au" mentar al mínimo todas las alarmas').

Un último caso normativo que voy a comentar en este trabajo y que obliga a la reflexión gramatical es el que responde a las estructuras del tipo siguiente:

_- *Eso es fácil de resolverlo / Eso es fácil de resolver / Eso es fácil resolverlo.

Sabemos que, desde el punto de vista normativo, solo la primera construcción es incorrecta; y lo es porque la gramática del español nos dice que con los adjetivos fácil, difícil, entre otros, los infinitivos que las complementan tienen forma activa pero valor pasivo; o sea, son deponentes. Su valor pasivo es lo que impide que se puedan construir con complemento directo (en este caso, lo). Por ello, la estructura conrecta correspondiente es la de Eso es fácil de resolver, donde resolver significa 'ser resuelto'. La tercera construcción es totalmente legítima, pues en ella la secuencia de infinitivo (resolverlo) es el sujeto del predicado es fácil, y no un complemento del adjetivo; en estas estructuras, el infinitivo es activo en forma y significado, por lo que el pronombre lo es su complemento directo, y el demostrativo eso se constituye en un tópico gramatical.

Con todas estas cuestiones normativas comentadas en este trabajo (podría haber comentado muchas más), he intentado señalar la importancia de los planteamientos normativos en el ámbito gramatical por cuanto obligan a reflexiones profundas. 